\title{
MODELING OF EXTERNAL CYLINDRICAL GRINDING PROCESS USING T1 TOOL STEEL
}

\author{
Tuan-Linh Nguyen \\ Department of Mechanical Engineering \\ Hanoi University of Industry \\ 298 Cau Dien str., Bac Tu Liem District, Hanoi City, Vietnam, 10000 \\ nguyentuanlinh@haui.edu.vn
}

\begin{abstract}
The selection of the optimal external cylindrical grinding conditions importantly contributes to increase of productivity and quality of the products. The external cylindrical grinding is a method of finishing machine elements surface with an indeterminate blade shape. External cylindrical grinding can process surfaces that require high gloss and precision, although it can also be used to remove large surplus stock. Therefore, multi objective optimization for the external cylindrical grinding process is a problem with high complexity. In this study, an experimental study was performed to improve the productivity and quality of grinding process. By using the experimental date, the surface roughness, cutting force, and vibrations were modeled. To achieve the minimum value of surface roughness and maximum value of material removal rate, the optimal values of external cylindrical grinding conditions were determined by using the combination of Genetic Algorithms (GAs) and weighting method. The optimum values of surface roughness and material removal rate are $0.510 \mu \mathrm{m}$ and $5.906 \mathrm{~mm}^{2} / \mathrm{s}$, respectively. The obtained optimal values of cutting parameters were a feed rate of $0.3 \mathrm{~mm} / \mathrm{rev}$, a workpiece speed of $188.1 \mathrm{rpm}$, a cutting depth of $0.015 \mathrm{~mm}$, and a workpiece Rockwell hardness of $54.78 \mathrm{HRC}$. The optimal values of cutting parameters, and workpiece hardness were successfully verified by comparing of experimental and predicted results. The approach method of this study can be applied in industrial machining to improve the productivity and quality of the products in external cylindrical grinding process of the T1 tool steel.
\end{abstract}

Keywords: External cylindrical grinding, Modeling, Genetic Algorithms, productivity, quality, surface roughness, workpiece Rockwell hardness, cutting force, vibration.

DOI: $10.21303 / 2461-4262.2021 .001698$

\section{Introduction}

Machining process in general and the grinding process in particular, the productivity and surface roughness are the two important goals that the engineers and workers always want to aim. Depending on the stages of the grinding process the objective can be productivity or surface roughness, but the desire during the grinding process is to achieve both productivity and surface roughness. The optimal problem of two or more goals is called the multi-objective optimization problem. This is a complex problem containing many boundary conditions and constraints with large search space, so to solve this problem requires an appropriate algorithm.

Many studies have been conducted to investigate the influence of cutting parameters on the surface roughness, cutting forces, vibrations, and material removal rate. The effective evaluation of the optimization process was achieved by rapid-working in-process and post-process measurement systems [1]. A novel modelling schemes and optimization methods for surface roughness was proposed based on evolutionary algorithms in the grinding processes [2]. An available model with single criteria material removal rate was applied to obtain the optimum grinding parameters for silicon carbide grinding process using the particle swarm optimization algorithm [3]. A combination method of the target tree method and the genetic algorithm was used to optimize the grinding process [4].

In multi-objective optimization of grinding process, there are more things that have done with the real application. A better solution technique with scatter search approach was proposed for multi-objective optimization of surface grinding operations [5]. An approach using integrated Genetic Algorithm-Neural Network system was applied to optimize the creep feed grinding process. The aim of this study was determination of the maximal metal removal rate (MRR) and the minimum of the surface roughness $\left(R_{a}\right)$ in creep feed grinding process [6].

An optimization approach based on enhanced Pareto particle swarm optimization algorithm and local climbing optimization technique was proposed to solve the optimization problem in the grinding processes [7]. The ant colony algorithm approach was successfully applied to solve 
the optimization problem in the grinding processes [8]. A combination method of genetic algorithm and weighted objective function based on the optimization procedure was proposed to optimize for the surface grinding process [9], to model and optimize the parameters in chemotherapy [10], to focus mainly on optimization technique and engineering application [11], to optimize the part flow time between machines, processing time of the part, throughput of the plant [12].

In this study, a combination method of genetic algorithms (GAS) and weighting methods was proposed to solve the multi-objective optimization problem. The surface roughness function $\left(R_{a}\right)$ and material removal rate function $\left(Q^{\prime}\right)$ were selected as the evaluation criteria in grinding process. The constraint functions including cutting force $\left(F_{y}\right.$ and $\left.F_{z}\right)$, and vibration function $(A)$ were built using experimental data of external cylindrical grinding the T1 tool steel. The achieved results are important bases to select the suitable machining conditions to achieve the highest productivity and the smallest surface roughness in external cylindrical grinding process.

\section{Materials and methods}

2. 1. Multi-Objective optimization method

2. 1. 1. Multi-Objective optimization process

Fig. 1 described the multi-objective optimization process in the grinding process.

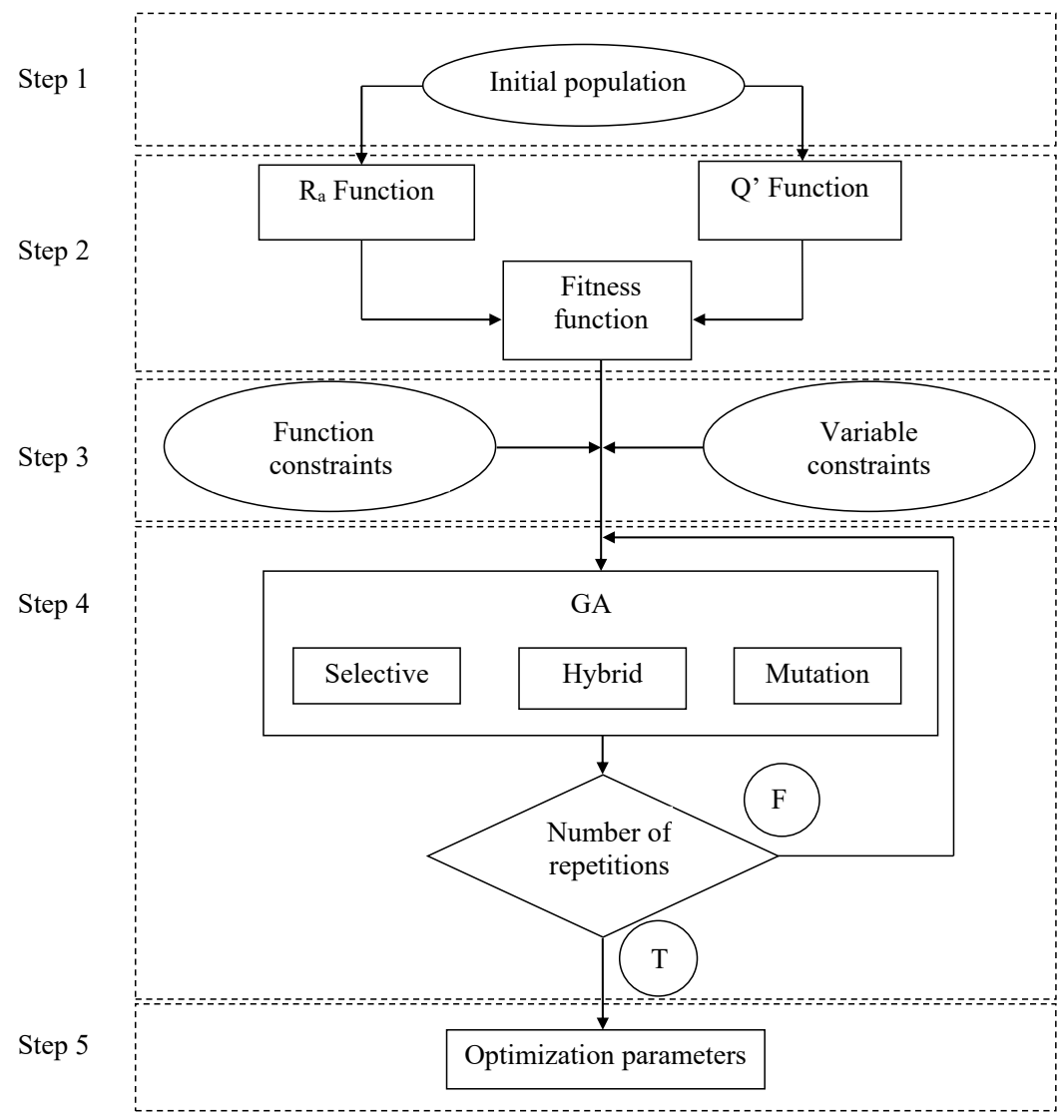

Fig. 1. Block diagram to solve the multi-objective optimization problem for external cylindrical grinding process

The steps to solve the optimization problem were presented as following:

- Step 1. Setting the initial population: The initial values of machining parameters and the hardness of the workpiece material are the initial values of the optimization process.

- Step 2. Determination of objective functions: Surface roughness $\left(R_{a}\right)$ and material removal rate $\left(Q^{\prime}\right)$ function are modeled as the single objective functions. The adaptive function was built as a multi-objective function, which is a function of single-objective functions. 
- Step 3. Determination of boundary conditions: The boundary conditions include the function constraints and variable constraints. The function constraints in this problem included vibration and force functions, variable constraints are cutting parameters and machining material stiffness.

- Step 4. Solving the optimization problem: This step consists of the selection, the hybridization, and the mutation of the genetic algorithm. The number of iterations to create the best individual among selected individuals to find the optimal parameters.

- Step 5. Obtaining the optimum values.

\section{1. 2. Multi-objective functions}

The grinding process is divided into rough grinding and fine grinding. With rough grinding, the greatest productivity is concerned while maintaining a certain surface roughness. With fine grinding, the goal optimization process is to achieve the smallest surface roughness and to ensure the maximum value of machining productivity [6]. Thus, the grinding process needs to satisfy as follows:

- minimum in surface roughness;

- maximum of machining productivity, or maximum of material removal.

Therefore, it is possible to build a multi-objective function by weighting method as by the eq. (1):

$$
M=w_{1} \cdot \frac{R_{a}}{R_{a}^{*}}-w_{2} \cdot \frac{Q^{\prime}}{Q^{*}},
$$

where $R_{a}$ is the surface roughness function.

The surface roughness function is modeled experimentally on external cylindrical grinding with $\mathrm{T} 1$ tool steel as by the eq. (2):

$$
R_{a} \leq R_{a}^{*}
$$

$R_{a}^{*}$ is the limit of surface roughness. That is the value of surface roughness when replacing the upper boundary condition of the variables into the mathematical function of surface roughness.

$Q^{\prime}$ is the material removal rate function. $Q^{\prime}$ is determined by the eq. (3):

$$
Q^{\prime} \geq Q^{*}
$$

where $Q^{*}$ is the limit value of the material removal rate criteria.

\section{1. 3. The Constraints}

Functional constraints. The constraints on cutting force and vibration functions are determined by the eq. (4) to the eq. (6):

$$
\begin{gathered}
F_{y}=f\left(S_{d}, t, H R C\right) \leq F_{y}^{*}, \\
F_{z}=f\left(S_{d}, t, H R C\right) \leq F_{z}^{*}, \\
A=f\left(S_{d}, n_{w}, t\right) \leq A^{*} .
\end{gathered}
$$

Variable constraints [12]. The variable constraints are determined by the eq. (7) to the eq. (10). Feed rate:

$$
S_{d}^{\min } \leq S_{d} \leq S_{d}^{\max }
$$

Workpiece speed:

$$
n_{w}^{\min } \leq n_{w} \leq n_{w}^{\max } .
$$


Cutting depth:

$$
t_{\min } \leq t \leq t_{\max }
$$

Hardness of workpiece material:

$$
H R C_{\min } \leq H R C \leq H R C_{\max },
$$

where:

- $S_{d}-$ Axial Feed rate ( $\left.\mathrm{mm} / \mathrm{rev}\right)$

$-n_{w}-$ Rotation speed of workpiece (rpm);

$-t$ - Cutting depth (mm);

- HRC - Rockwell hardness of workpiece;

$-F_{y}$ - Amplitude of cutting force along the $O y(\mathrm{~N})$;

$-F_{z}$ - Amplitude of cutting force along the $O z(\mathrm{~N})$;

- $A$ - Acceleration amplitude $\left(\mathrm{m} / \mathrm{s}^{2}\right)$;

$-F_{y}^{*}, F_{z}^{*}, A^{*}$ are the boundary limits of the normal force, tangential force and vibration amplitude, respectively, which are determined by the strength, firmness of the machine, and the cutting tool.

\section{1. 4. The Weights}

Weights of surface roughness and machining productivity are $\omega_{1}$ and $\omega_{2}$. These values that are in the range $(0,1)$, allow to determine the corresponding effects of $R_{a}$ and $Q^{\prime}$. The sum of these coefficients is 1 as by the eq. (11) [13].

$$
w_{1}+w_{2}=1
$$

If the priority of the variables is not the same, the variable with a larger coefficient will be more important. Depending on the purpose of the grinding process, if it is a rough grinding process, the productivity will be an important goal, the coefficient $w_{2}$ will be larger. On the contrary, if it is a finish grinding process, the surface roughness is an important goal, so the coefficient $w_{1}$ will be larger.

\section{2. Experimental setup}

\section{2. 1. Experimental machine}

The external cylindrical grinding machine MEG-120 MAGNUM CUT was used to perform the experiments as illustrated in Fig. 2.

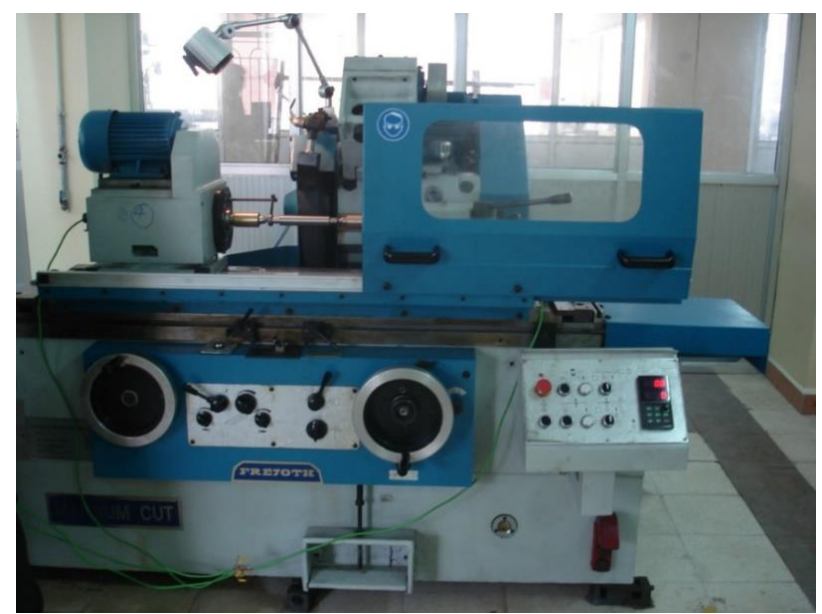

Fig. 2. External cylindrical grinding machine MEG-112 
The rotation speed of grinding wheel is $2000 \mathrm{rpm}$, the rotation speed of workpiece is $650 \mathrm{rpm}$, the movement speed of the stepless machine table is from 0.1 to 5 meters per minute $(\mathrm{mm} / \mathrm{rev})$.

\section{2. Workpiece and grinding wheel}

The experimental workpieces with the diameter of $40 \mathrm{~mm}$ was used in grinding process as described in Fig. 3. The workpiece material is T1 tool steel that was heat treated to achieve the hardness of 40, 50, and $60 \mathrm{HRC}$. The composites of T1 tool steel was listed in Table 1.

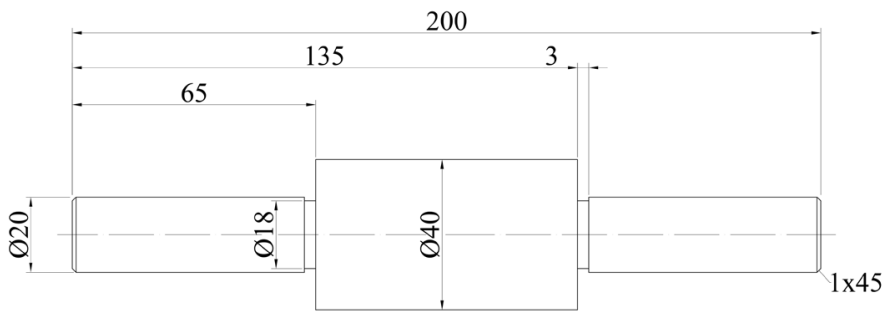

Fig. 3. Workpiece dimensions

Table 1

The components of $\mathrm{T} 1$ tool steel

\begin{tabular}{cc}
\hline Steel brand & Chemical composition (\%) \\
\hline ASTM: T1 tool steel & $\mathrm{C} 0.7-0.8, \mathrm{Si} \leq 0,4, \mathrm{Mn} \leq 0.4, \mathrm{Cr} 3.8-4.4, \mathrm{~V} 1-1.4, \mathrm{~W} 17.5-19$
\end{tabular}

The experimental grinding wheel has the size $400 \times 50 \times 203$, 3-grain diamond stone dressing tool with size: $8.5 \times 40$ using the grinding method with the center of the feed rate.

\section{2. 3. Measurement system}

MITUTOYO-SJ-400 Surface Roughness Tester (Japan) was used to measure the surface roughness of the workpiece as illustrated in Fig. 4. The cut-off length and evaluation length were fixed at $0.8 \mathrm{~mm}$ and $4 \mathrm{~mm}$, respectively. The surface roughness was measured parallel to the machined surface repeated three times following three repeated times of each cutting test. The average values of the measurements were evaluated.

The setting of cutting forces measurement is illustrated in Fig. 5.

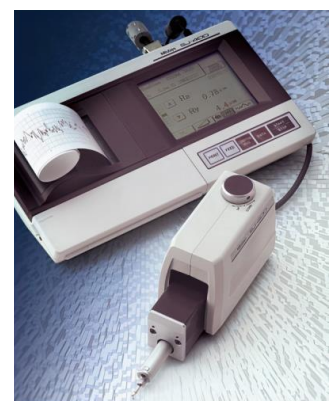

Fig. 4. The surface roughness tester Mitutoyo Surflest SJ-400

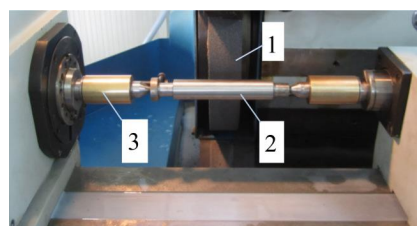

$a$

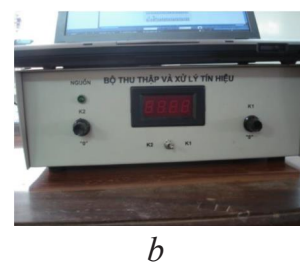

$b$

Fig. 5. The setting of cutting force measurement: $a$ - Grinding wheel (1), workpiece (2) and Force sensor (3); $b$ - Signal processing system 
The vibration measurement system that included the acceleration sensor Triaxial DeltaTron Accelerometer with TEDS Type 4525-B-001, the stored data LAN-XI, and the PULSE FFT 7770 module was used to measure the machine-tool vibrations. The detail is illustrated in Fig. 6 [14].

All the measuring devices are connected simultaneously to ensure the system synchronization.

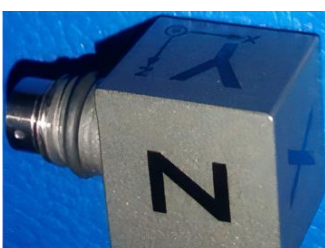

$a$

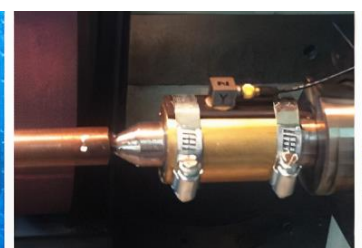

$b$

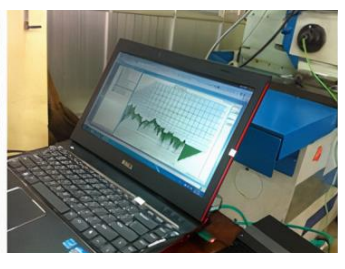

c

Fig. 6. Setting of vibration measurement:

$a$-Vibration sensor; $b$ - Measurement position; $c$ - Data processing system

\section{2. 4. Design of the experimental matrix}

From the trial grinding tests, the effect of the grinding conditions and workpiece hardness on the surface roughness, the cutting forces, and the vibrations were determined. The important factors that influence on the surface roughness are the axial feed rate, the workpiece speed, the cutting depth, and the workpiece hardness. There are three important factors (axial feed rate, cutting depth, and workpiece hardness) that influence on the cutting forces. And there are three important factors (axial feed rate, workpiece speed, and cutting depth) that influence on the vibration. So, the levels of experimental factors and the experiment design of this study were listed from Tables 2-7.

Table 2

Machining parameters and their levels in surface roughness measurement

\begin{tabular}{ccccc}
\hline \multirow{2}{*}{ Factors } & \multirow{2}{*}{ Unit } & \multicolumn{3}{c}{ Levels } \\
\cline { 3 - 5 } & & Level 1 (-1) & Level 1 (0) & Level 1(1) \\
\hline Axial feed rate $S_{d}$ & $\mathrm{~mm} / \mathrm{rev}$ & 0.3 & 0.4 & 0.5 \\
Workpiece speed $n_{w}$ & $\mathrm{rpm}$ & 100 & 150 & 200 \\
Cutting depth $t$ & $\mathrm{~mm}$ & 0.005 & 0.015 & 0.025 \\
Workpiece hardness & $\mathrm{HRC}$ & 40 & 50 & 60
\end{tabular}

Table 3

Experimental matrix and measured results of surface roughness

\begin{tabular}{|c|c|c|c|c|c|c|c|c|c|}
\hline \multirow{3}{*}{ No. } & \multicolumn{8}{|c|}{ Input factors } & \multirow{3}{*}{$R_{a}(\mu \mathrm{m})$} \\
\hline & \multicolumn{4}{|c|}{ Coded factors } & \multicolumn{4}{|c|}{ Machining parameters } & \\
\hline & $X_{1}$ & $X_{2}$ & $X_{3}$ & $X_{4}$ & $S_{d}(\mathrm{~mm} / \mathrm{rev})$ & $n_{w}(\mathbf{r p m})$ & $t(\mathrm{~mm})$ & HRC & \\
\hline 1 & -1 & -1 & -1 & -1 & 0.3 & 100 & 0.005 & 40 & 0.32 \\
\hline 2 & +1 & -1 & -1 & -1 & 0.5 & 100 & 0.005 & 40 & 0.35 \\
\hline 3 & -1 & +1 & -1 & -1 & 0.3 & 200 & 0.005 & 40 & 0.37 \\
\hline 4 & +1 & +1 & -1 & -1 & 0.5 & 200 & 0.005 & 40 & 0.41 \\
\hline 5 & -1 & -1 & +1 & -1 & 0.3 & 100 & 0.025 & 40 & 0.56 \\
\hline 6 & +1 & -1 & +1 & -1 & 0.5 & 100 & 0.025 & 40 & 0.6 \\
\hline 7 & -1 & +1 & +1 & -1 & 0.3 & 200 & 0.025 & 40 & 0.66 \\
\hline 8 & +1 & +1 & +1 & -1 & 0.5 & 200 & 0.025 & 40 & 0.69 \\
\hline 9 & -1 & -1 & -1 & +1 & 0.3 & 100 & 0.005 & 60 & 0.28 \\
\hline 10 & +1 & -1 & -1 & +1 & 0.5 & 100 & 0.005 & 60 & 0.31 \\
\hline 11 & -1 & +1 & -1 & +1 & 0.3 & 200 & 0.005 & 60 & 0.34 \\
\hline 12 & +1 & +1 & -1 & +1 & 0.5 & 200 & 0.005 & 60 & 0.37 \\
\hline 13 & -1 & -1 & +1 & +1 & 0.3 & 100 & 0.025 & 60 & 0.56 \\
\hline 14 & +1 & -1 & +1 & +1 & 0.5 & 100 & 0.025 & 60 & 0.59 \\
\hline 15 & -1 & +1 & +1 & +1 & 0.3 & 200 & 0.025 & 60 & 0.62 \\
\hline 16 & +1 & +1 & +1 & +1 & 0.5 & 200 & 0.025 & 60 & 0.68 \\
\hline
\end{tabular}


Table 4

Machining parameters and their levels in cutting force measurement

\begin{tabular}{ccccc}
\hline \multirow{2}{*}{ Factors } & Unit & \multicolumn{3}{c}{ Levels } \\
\cline { 3 - 5 } & & Level 1 (-1) & Level 2 (0) & Level 3 (1) \\
\hline Axial feed rate $S_{d}$ & $\mathrm{~mm} / \mathrm{rev}$ & 0.3 & 0.4 & 0.5 \\
Cutting depth $t$ & $\mathrm{~mm}$ & 0.005 & 0.015 & 0.025 \\
Workpiece hardness & HRC & 40 & 50 & 60
\end{tabular}

Table 5

Experimental matrix and measured results of cutting forces

\begin{tabular}{|c|c|c|c|c|c|c|c|c|}
\hline \multirow{3}{*}{ No. } & \multicolumn{6}{|c|}{ Input factors } & \multirow{2}{*}{\multicolumn{2}{|c|}{ Performance measures }} \\
\hline & \multicolumn{3}{|c|}{ Coded factors } & \multicolumn{3}{|c|}{ Machining parameters } & & \\
\hline & $X_{1}$ & $X_{2}$ & $X_{3}$ & $S_{d}(\mathrm{~mm} / \mathrm{rev})$ & $t(\mathrm{~mm})$ & HRC & $F_{y}(\mathrm{~N})$ & $F_{z}(\mathrm{~N})$ \\
\hline 1 & -1 & -1 & -1 & 0.3 & 0.005 & 40 & 7.10 & 3.45 \\
\hline 2 & +1 & -1 & -1 & 0.5 & 0.005 & 40 & 12.33 & 4.24 \\
\hline 3 & -1 & +1 & -1 & 0.3 & 0.025 & 40 & 12.85 & 5.15 \\
\hline 4 & +1 & +1 & -1 & 0.5 & 0.025 & 40 & 25.43 & 9.33 \\
\hline 5 & -1 & -1 & +1 & 0.3 & 0.005 & 60 & 16.55 & 6.23 \\
\hline 6 & +1 & -1 & +1 & 0.5 & 0.005 & 60 & 20.64 & 7.78 \\
\hline 7 & -1 & +1 & +1 & 0.3 & 0.025 & 60 & 19.36 & 7.45 \\
\hline 8 & +1 & +1 & +1 & 0.5 & 0.025 & 60 & 30.32 & 14.21 \\
\hline
\end{tabular}

Table 6

Machining parameters and their levels in vibration measurement

\begin{tabular}{ccccc}
\hline \multirow{2}{*}{ Factors } & Unit & \multicolumn{3}{c}{ Levels } \\
\cline { 3 - 5 } & & Level 1 (-1) & Level 2 (0) & Level 3 (1) \\
\hline Axial feed rate $S_{d}$ & $\mathrm{~mm} / \mathrm{rev}$ & 0.3 & 0.4 & 0.5 \\
Workpiece speed $n_{w}$ & $\mathrm{rpm}$ & 100 & 150 & 200 \\
Cutting depth $t$ & $\mathrm{~mm}$ & 0.005 & 0.015 & 0.025
\end{tabular}

Table 7

Experimental matrix and measured results of vibration

\begin{tabular}{|c|c|c|c|c|c|c|c|}
\hline \multirow{3}{*}{ No. } & \multicolumn{6}{|c|}{ Input factors } & \multirow{3}{*}{$A\left(\mathrm{~m} / \mathrm{s}^{2}\right)$} \\
\hline & \multicolumn{3}{|c|}{ Coded factors } & \multicolumn{3}{|c|}{ Machining parameters } & \\
\hline & $X_{1}$ & $X_{2}$ & $X_{3}$ & $S_{d}(\mathrm{~mm} / \mathrm{rev})$ & $n_{w}(\mathbf{r p m})$ & $t(\mathbf{m m})$ & \\
\hline 1 & -1 & -1 & -1 & 0.3 & 100 & 0.005 & 0.766 \\
\hline 2 & +1 & -1 & -1 & 0.5 & 100 & 0.005 & 0.888 \\
\hline 3 & -1 & +1 & -1 & 0.3 & 200 & 0.005 & 0.913 \\
\hline 4 & +1 & +1 & -1 & 0.5 & 200 & 0.005 & 0.998 \\
\hline 5 & -1 & -1 & +1 & 0.3 & 100 & 0.025 & 0.933 \\
\hline 6 & +1 & -1 & +1 & 0.5 & 100 & 0.025 & 1.237 \\
\hline 7 & -1 & +1 & +1 & 0.3 & 200 & 0.025 & 1.108 \\
\hline 8 & +1 & +1 & +1 & 0.5 & 200 & 0.025 & 1.319 \\
\hline
\end{tabular}

The Tables 2-7 above show the measured values of roughness, cutting force and vibration at different test levels. 


\section{Results}

\section{1. The regression and verification of experimental models}

3. 1. 1. Regression of surface roughness model

The experimental results were stored as in Table $\mathbf{3}$ for the surface roughness, Table $\mathbf{5}$ for the cutting forces, and Table 7 for the vibration. By analyzing of the experimental data, the surface roughness in the grinding process was modeled as the exponential function (12). The verification results of surface roughness model were described in Fig. 7. As seen from this figure, the predicted results were quite close to the experimental results. There is a quite good relation between predicted values and test values. The surface roughness models can be used to optimize the grinding parameters of the grinding process.

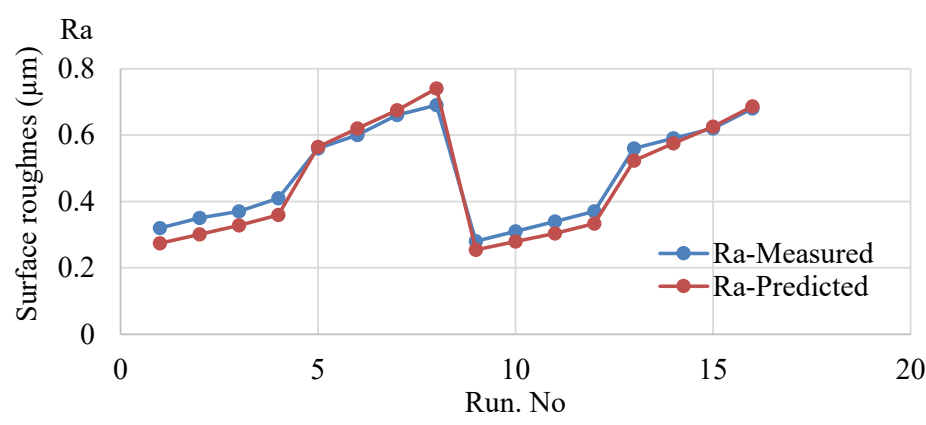

Fig. 7. Measured and predicted results of surface roughness

The surface roughness model in exponential function:

$$
R_{a}=2.2463 S_{d}^{0.1559} n_{w}^{0.2204} t^{0.4277} H R C^{-0.1605}
$$

To assess the appropriateness of the regression equation is to check whether the model obtained correctly describes our experiments or not. Let's use Fisher standard to compare:

$$
F_{\text {cal }}<F_{\text {tab }}\left(P, k_{1}, k_{2}\right),
$$

in which $k_{1}=N-n-1 ; k_{2}=N(m-1) ; N$ - number of experiments $(N=8) ; n$ - number of factors affecting the test results $(n=3) ; m$ - number of repetitions of the experiment $(m=3)$. So: $k_{1}=4 ; k_{2}=16$ :

$$
F_{c a l}=\frac{S_{c}^{2}}{S_{r}^{2}} .
$$

Compatible variance:

$$
S_{c}^{2}=\frac{m}{N-n-1} \sum_{i=1}^{N}\left(\bar{y}_{i}-\widehat{y}_{t b}\right)^{2}
$$

Repetitive variance:

$$
S_{r}^{2}=\frac{1}{N} \sum_{i=1}^{n} S_{i}^{2}=\frac{1}{N(m-1)} \sum_{i=1}^{N} \sum_{j=1}^{m}\left(y_{i j}-\bar{y}_{i}\right)^{2},
$$

where $\bar{y}_{i}$ - experimental results No. $i$ calculated according to the regression equation; $\bar{y}_{i}-$ the average value of $\mathrm{m}$ times experiments in the $i^{\text {th }}$ experiment; $y_{i j}$ - the value of the $i^{\text {th }}$ experiment in the $j^{\text {th }}$ iteration; $\bar{y}_{i}-\hat{y}_{i}-$ error between theory and experiment in $i^{\text {th }}$ experiment.

Basing on experimental results according to the regression eq. (12), the evaluation values of the surface roughness regression model $\left(R_{a}\right)$ were calculated as following:

$$
S_{c}^{2}=0.1981 ; \quad S_{r}^{2}=0.1102
$$


According to the Fisher standard [15]:

$$
F_{c a l}=1.797<F_{t a b}(11,32,0.95)=2.1 \text {. }
$$

Thus, eq. (12) is consistent with reality.

\section{1. 2. Regression of cutting force models}

By the same way, the cutting forces in the grinding process were modeled as the exponential functions (17), (18). The verification results of cutting force models were described in. As seen from Fig. 8, 9, the predicted results were quite close to the experimental results. The cutting force models can be used to optimize the grinding parameters of the grinding process.

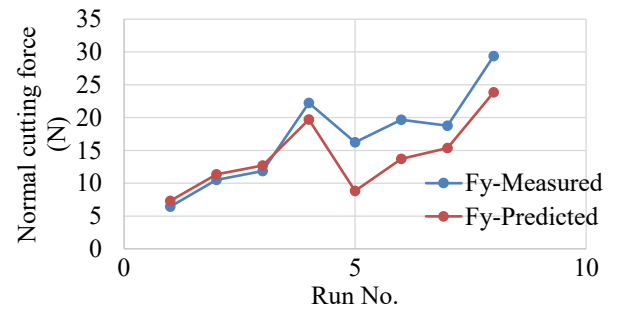

Fig. 8. Measured and predicted results of normal cutting force

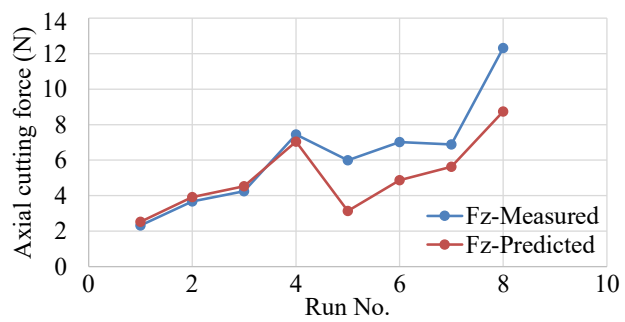

Fig. 9. Measured and predicted results of axial cutting force

The normal cutting force model in exponential function:

$$
F_{y}=36.445 S_{d}^{0.9324} t^{0.3507} H R C^{0.3373}
$$

The axial cutting force model in exponential function:

$$
F_{z}=13.397 S_{d}^{0.8176} t^{0.3655} H R C^{0.3662} \text {. }
$$

Basing on experimental results according to the regression (17), the evaluation values of the cutting force regression model $\left(F_{y}\right)$ were calculated as following:

$$
S_{c}^{2}=0.0623 ; S_{r}^{2}=0.0534
$$

According to the Fisher standard [14]:

$$
F_{c a l}=1.17<F_{t a b}(4,16,0.95)=3.0
$$

Basing on experimental results according to the regression (18), the evaluation values of the cutting force regression model $\left(F_{z}\right)$ were calculated as following:

$$
S_{C}^{2}=0.0599 ; \quad S_{r}^{2}=0.0532 \text {. }
$$

So, $F_{c a l}=1.13<F_{t a b}(4,16,0.95)=3.0$. Thus, eq. (17), (18) are consistent with reality. 


\section{1. 3. Regression of vibration model}

By the same way, the vibration in the grinding process was modeled as the exponential function (19). The verification results of surface roughness model were described in Fig. 10. As seen from this figure, the predicted results were quite close to the experimental results. The vibration models can be used to optimize the grinding parameters of the grinding process.

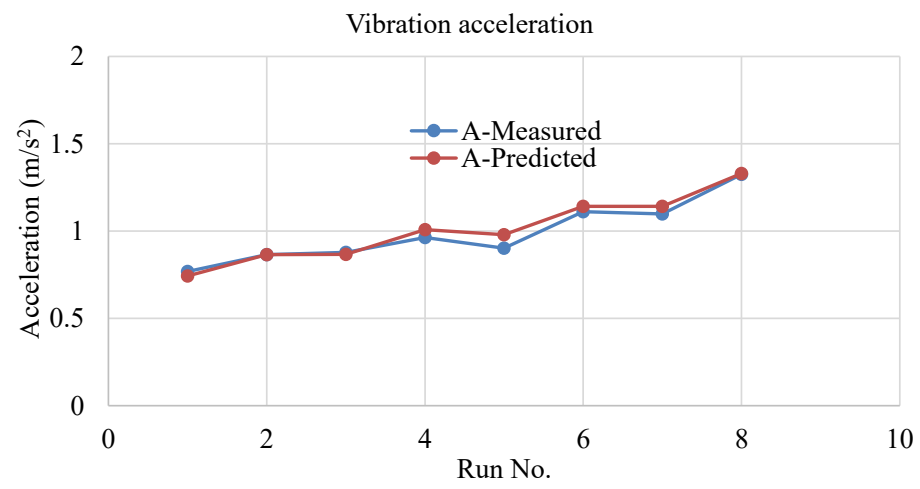

Fig. 10. Measured and predicted results of amplitude vibration

The amplitude vibration model in exponential function:

$$
A=1.2409 S_{d}^{0.3397} n_{w}^{0.1908} H R C^{0.1809}
$$

Basing on experimental results according to the regression eq. (19), the evaluation values of the vibration regression model $(A)$ were calculated as following:

$$
S_{c}^{2}=0.0139 ; \quad S_{r}^{2}=0.0135 \text {. }
$$

According to the Fisher standard [14]:

$$
F_{c a l}=1.03<F_{t a b}(4,16,0.95)=3.0 .
$$

Thus, eq. (19) is consistent with reality.

\section{2. Multi-Objective optimization of Cutting Conditions in Grinding process}

3. 2. 1. The Objective functions

The surface roughness function. The surface roughness function is constructed experimentally on external cylindrical grinding as by the eq. (12). Is the value when replacing the upper boundary condition of the variables into the mathematical functions as above. In this study $R_{a}^{*}=0.69 \mu \mathrm{m}$.

The material removal rate function. The material removal rate in grinding process was calculated by the eq. (20) to the eq. (23):

$$
Q=v_{w} \cdot t \cdot b_{s},
$$

$t$ is the cutting depth, mm; $b_{s}$ is the width of the grinding wheel. Due to the constant width of the grinding wheel, the material removal rate function can be calculated as by the eq. (21):

$$
Q^{\prime}=v_{w} \cdot t .
$$

Workpiece speed $v_{w}$ is calculated according to the eq. (22).

$$
v_{w}=\frac{\pi d_{w} n_{w}}{60} .
$$


So,

$$
Q^{\prime}=\frac{\pi d_{w} n_{w \omega} t}{60},
$$

where $d_{\tau}$ is the diameter of the workpiece; $n_{\varpi}$ is the number of revolutions of the workpiece.

Condition $Q^{\prime 3} Q^{*}$. In this case, $Q^{*}=0.523 \mathrm{~mm}^{2} / \mathrm{s}$.

\section{2. 2. The constraints}

Functional constraints. The function constraints on cutting force and vibration functions are determined by the eq. (24) to the eq. (29):

$$
\begin{gathered}
F_{y}=f\left(S_{d}, t, H R C\right) \leq F_{y}^{*}=100 \mathrm{~N}, \\
F_{z}=f\left(S_{d}, t, H R C\right) \leq F_{z}^{*}=50 \mathrm{~N}, \\
A=f\left(S_{d}, n_{\mathrm{w}}, t\right) \leq A^{*}=2 \mathrm{~m} / \mathrm{s}^{2} .
\end{gathered}
$$

Variable constraints [9]. The variable constraints on cutting conditions and workpiece hardness are determined by the eq. (27) to the eq. (30). Feed rate:

$$
0.3 \leq S_{d} \leq 0.5(\mathrm{~mm} / \mathrm{rev})
$$

Rotation speed of workpiece:

$$
100 \leq n_{w} \leq 200(\mathrm{rpm}) .
$$

Cutting depth:

$$
0.0025 \leq t \leq 0.025(\mathrm{~mm})
$$

Hardness of machining materials:

$$
40 \leq H R C \leq 60 .
$$

The program is programmed directly on MATLAB software. Running the program with the module Optimization Tool/Multi objective optimization using Genetic Algorithm for grinding process of $\mathrm{T} 1$ tool steel.

\section{2. 3. Weight}

In this study, considering the priority of the variables to be the same, the coefficient $w_{1}$ equal the coefficient $w_{2}$. Then the multi-objective function can be expressed as by the eq. (31):

$$
M=0.5 \frac{R_{a}}{R_{a}^{*}}-0.5 \frac{Q^{\prime}}{Q^{*}} .
$$

In case to prioritize a goal, it is possible to choose a greater weight but still have to ensure that the sum of the weights is 1 .

\section{2. 4. The optimization results}

The optimization results were stored in Tables 8, 9. The Genetic Algorithm graphs were described in Fig. 11. The results of the program show the stability of the variable values. Although the values changed, the range is very small. Hence, the average values were employed in the run lead to a fast convergence speed. However, the rapid convergence rate is also the disadvantage of the 
algorithm. If the convergence is too fast, the reliable information growing in the population will be overlooked and lead to a locally optimal solution. To overcome this disadvantage, let's first select the number of generations for the first run and then increase in the number of generations until the graph are always a straight line that is to achieve the global optimal value.

Results with 5 running times show that the optimal value for each run is variable but the difference is not so much. The average value of the runs can be used to predict the values of surface roughness and the material removal rate Fig. 11.

Table 8

Results of the program run with $\mathrm{T} 1$ tool steel

\begin{tabular}{ccccc}
\hline Variable & $\boldsymbol{S}_{\boldsymbol{d}}(\mathbf{m m} / \mathbf{r e v})$ & $\boldsymbol{n}_{\text {w }}(\mathbf{r p m})$ & $\boldsymbol{t}(\mathbf{m m})$ & 0.015 \\
\hline $1^{\text {st }}$ run & 0.3 & 187.25 & 0.014 & 54.5 \\
$2^{\text {nd }}$ run & 0.3 & 189.16 & 0.015 & 54.3 \\
$3^{\text {th }}$ run & 0.3 & 187.01 & 0.014 & 55.2 \\
$4^{\text {th }}$ run & 0.3 & 193.10 & 0.016 & 54.7 \\
$5^{\text {th }}$ run & 0.3 & 183.76 & 55.2
\end{tabular}

Table 9

Results of running the program, taking the average values after 5 runs

\begin{tabular}{cccccccccc}
\hline Parameters & $\boldsymbol{S}_{\boldsymbol{d}}(\mathbf{m m} / \mathbf{r e v})$ & $\boldsymbol{n}_{w}(\mathbf{r p m})$ & $\boldsymbol{t}(\mathbf{m m})$ & $\mathbf{H R C}$ & $\boldsymbol{R}_{\boldsymbol{a}}(\boldsymbol{\mu m})$ & $\boldsymbol{F}_{\boldsymbol{y}}(\mathbf{N})$ & $\boldsymbol{F}_{z}(\mathbf{N})$ & $\boldsymbol{A}\left(\mathbf{m} / \mathbf{s}^{\mathbf{2}}\right)$ & $\boldsymbol{Q}^{\prime}\left(\mathbf{m m} \mathbf{m}^{2} / \mathbf{s}\right)$ \\
\hline Optimized values & 0.3 & 188.1 & 0.015 & 54.78 & 0.51 & 10.441 & 4.648 & 1.045 & 5.906 \\
Constraint values & $0.3 \div 0.5$ & $100 \div 200$ & $0.0025 \div 0.025$ & $40 \div 60$ & Min & 100 & 50 & 2 & Max
\end{tabular}

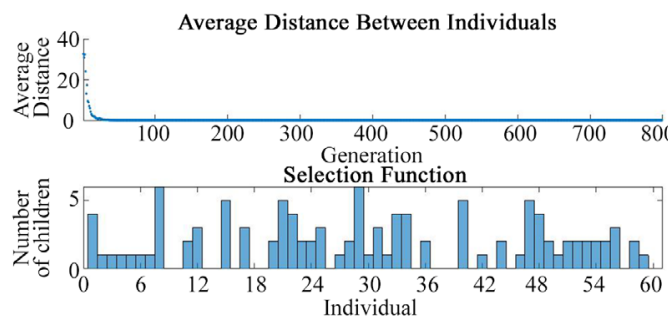

$a$

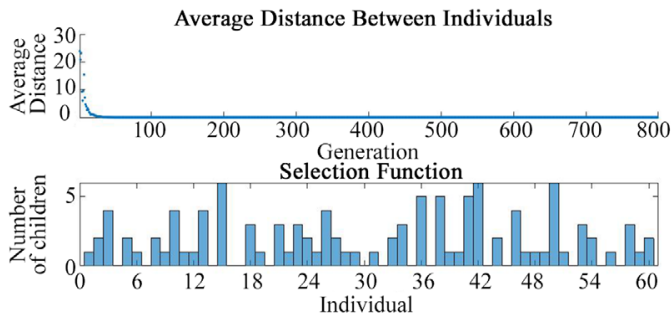

c
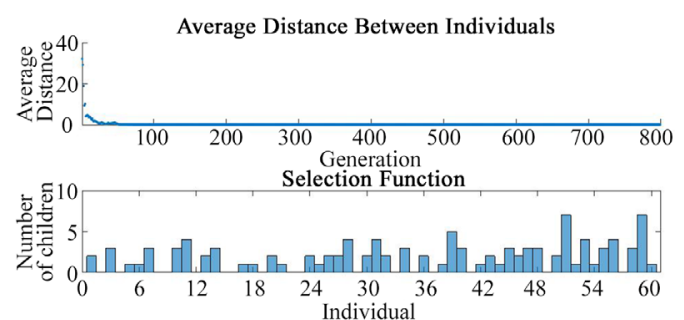

$b$

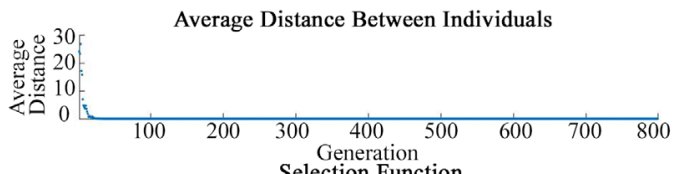

Selection Function

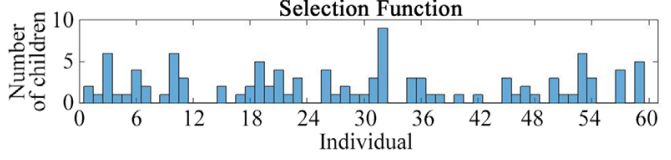

$d$

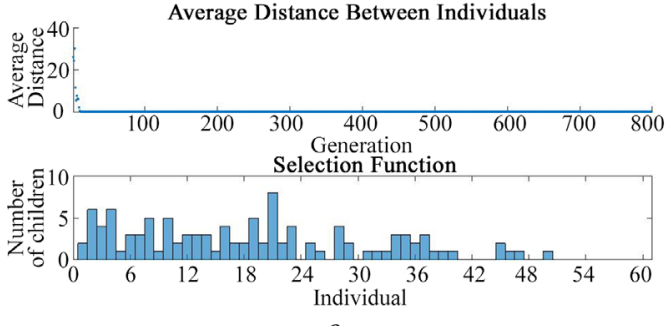

$e$

Fig. 11. Genetic algorithm graph for grinding T1 tool steel: $a$ - Time $1 ; b$ - Time 2; $c$-Time $3 ; d$ - Time $4 ; e$ - Time 5 
From the adaptive function, there is many optimization options by changing the coefficients $w_{1}, w_{2}$ depending on which priority for the target. For example, in a roughing process, it is necessary to prioritize productivity targets by choosing a large $w_{2}$ coefficient. Or when finishing requires a priority to achieve the target is the surface roughness let's choose a large $w_{1}$ coefficient. When $w_{1}$ or $\omega_{2}$ is zero, the problem becomes a single-objective problem.

\section{3. Experimental using the optimal values}

Using the optimal values of the cutting parameters and the hardness of the workpiece, the verification experiments were conducted. The comparison results of experimental and predicted values of surface roughness, cutting force amplitude, vibration amplitude, and material removal rate are calculated and listed in Table $\mathbf{1 0 .}$

Table 10

The predicted and experimental results with optimal parameters

\begin{tabular}{cccccc}
\hline Parameters & $\boldsymbol{R}_{\boldsymbol{a}}(\mathbf{m m})$ & $\boldsymbol{F}_{\boldsymbol{y}}(\mathbf{N})$ & $\boldsymbol{F}_{\boldsymbol{z}}(\mathbf{N})$ & $\boldsymbol{A}\left(\mathbf{m} / \mathbf{s}^{2}\right)$ & $\boldsymbol{Q}^{\prime}\left(\mathbf{m m}^{2} / \mathbf{s}\right)$ \\
\hline Experimental & 0.530 & 10.972 & 4.531 & 1.135 & 5.466 \\
Predicted & 0.510 & 10.441 & 4.648 & 1.045 & 5.906 \\
Error (\%) & 3.8 & 1.8 & 6.5 & 7.9 & 7.5
\end{tabular}

In Table 10, the maximum error is the error of vibration with $7.9 \%$. Minimum error is the error of normal cutting force with $1.8 \%$.

\section{Discussions of experimental results}

From mathematical models (12), (17)-(19) showed that surface roughness when external cylindrical grinding of T1 tool steel is proportional to cutting parameters but inversely proportional to machining material hardness. They also show that both the cutting force $F_{y}$ and $F_{z}$ are directly proportional to the cutting parameters and the hardness of the workpiece. In which, the normal cutting force $F_{y}$ is much greater than the tangential cutting force $F_{z}$. The large $F_{y}$ cutting force is due to the loss of energy to separate the chip from the part when there is the penetration of the grinding grain, the higher the hardness of the material, the more difficult the grinding ability of the grinding grain. In addition, vibration during outer circular grinding is also proportional to the cutting parameters.

The results from Table 10 showed that the prediction of surface roughness, cutting force amplitude, vibration amplitude, and material removal rate were very close to the experimental results. The maximum difference between predicted and experimental values was $7.9 \%$ (for vibration amplitude). So, the combination of GAs and weighting method that was proposed in this study can be applied to improve the productivity and reduce the surface roughness of the workpiece in external cylindrical grinding process using T1 tool steel.

Because grinding is the process of cutting materials including cutting, scratching and rubbing with abrasive particles at very high speeds, so the heat generated during the grinding process is quite large. However, in this study, the thermal model has not been built up during the grinding process, nor has the effect of heat on the surface roughness and machining productivity be evaluated when external cylindrical grinding. This is a difficult problem to do because the coolant must be used during the external cylindrical grinding process, so the use of existing thermometers will give inaccurate results. The solution is being researched and resolved in the future by us.

\section{Conclusion}

In this study, an experimental method was performed to model the surface roughness, cutting forces, and vibration, and to optimize the cutting parameters in the external cylindrical grinding process of the $\mathrm{T} 1 \mathrm{tool}$ steel. Depending on the analysis of experimental results, the conclusions of this study can be drawn as follows.

In the external cylindrical grinding process, the surface roughness, cutting force amplitude, and vibration amplitude were modeled as the exponential functions of cutting parameters (axial 
feed rate, workpiece speed, and cutting depth) and the workpiece hardness. These models were successfully verified by experimental results with very promising results.

A combination of GAs and weighting method was successfully applied to solve the multiobjective optimization problem. Using this proposed combination method, the productivity and surface roughness quality were improved.

The optimum values of input parameters were a feed rate of $0.3 \mathrm{~mm} / \mathrm{rev}$, a workpiece speed of $188.1 \mathrm{rpm}$, a cutting depth of $0.015 \mathrm{~mm}$, and a workpiece hardness of $54.78 \mathrm{HRC}$. Using these optimal values, the surface roughness and material removal rate were obtained to be $0.510 \mu \mathrm{m}$ and $5.906 \mathrm{~mm}^{2} / \mathrm{s}$, respectively. The optimal values were successfully verified by experimental results with very promising results. The maximum difference between predicted and experimental values was $7.9 \%$.

The proposed method of this study can be applied in industrial machining to improve the productivity and quality of the products in external cylindrical grinding process of the T1 tool steel, and can be extended to the other machining processes such as milling, turning, drilling, etc. and another workpiece, tool materials. These are the future studies.

\section{References}

[1] Brinksmeier, E., Tönshoff, H. K., Czenkusch, C., Heinzel, C. (1998). Modelling and optimization of grinding processes. Journal of Intelligent Manufacturing, 9 (4), 303-314. doi: https://doi.org/10.1023/a:1008908724050

[2] Lee, C. W., Shin, Y. C. (2000). Evolutionary modelling and optimization of grinding processes. International Journal of Production Research, 38 (12), 2787-2813. doi: https://doi.org/10.1080/002075400411484

[3] Lee, T. S., Ting, T. O., Lin, Y. J., Htay, T. (2006). A particle swarm approach for grinding process optimization analysis. The International Journal of Advanced Manufacturing Technology, 33 (11-12), 1128-1135. doi: https://doi.org/10.1007/s00170-006-0538-y

[4] Krishna, A. G., Rao, K. M. (2006). Multi-objective optimisation of surface grinding operations using scatter search approach. The International Journal of Advanced Manufacturing Technology, 29 (5-6), 475-480. doi: https://doi.org/10.1007/bf02729099

[5] Sedighi, M., Afshari, D. (2009). Creep feed grinding optimization by an integrated GA-NN system. Journal of Intelligent Manufacturing, 21 (6), 657-663. doi: https://doi.org/10.1007/s10845-009-0243-4

[6] Lin, X., Li, H. (2008). Enhanced Pareto Particle Swarm Approach for Multi-Objective Optimization of Surface Grinding Process. 2008 Second International Symposium on Intelligent Information Technology Application. doi: https://doi.org/ 10.1109/iita.2008.75

[7] Baskar, N., Saravanan, R., Asokan, P., Prabhaharan, G. (2004). Ants colony algorithm approach for multi-objective optimisation of surface grinding operations. The International Journal of Advanced Manufacturing Technology, 23 (5-6), 311-317. doi: https://doi.org/10.1007/s00170-002-1533-6

[8] Saravanan, R., Sachithanandam, M. (2001). Genetic Algorithm (GA) for Multivariable Surface Grinding Process Optimisation Using a Multi-objective Function Model. The International Journal of Advanced Manufacturing Technology, 17 (5), $330-338$. doi: https://doi.org/10.1007/s001700170167

[9] McCall, J. (2005). Genetic algorithms for modelling and optimisation. Journal of Computational and Applied Mathematics, 184 (1), 205-222. doi: https://doi.org/10.1016/j.cam.2004.07.034

[10] Mitchell, M. (1999). An Introduction to Genetic Algorithms. A Bradford Book, 221.

[11] Arora, P. K., Haleem, A., Singh, M. K., Kumar, H., Kaushik, M. (2014). Design of a Production System Using Genetic Algorithm. Procedia Technology, 14, 390-396. doi: https://doi.org/10.1016/j.protcy.2014.08.050

[12] Nee, A. Y. C. (Ed.) (2015) Handbook of Manufacturing Engineering and Technology. Springer-Verlag London, 3500. doi: https:// doi.org/10.1007/978-1-4471-4670-4

[13] Arora, J. S. (2012). Introduction to Optimum Design. Academic Press. doi: https://doi.org/10.1016/c2009-0-61700-1

[14] Nguyen, T.-L., Nguyen, N.-T., Hoang, L. (2020). A study on the vibrations in the external cylindrical grinding process of the alloy steels. International Journal of Modern Physics B, 34 (22n24), 2040150. doi: https://doi.org/10.1142/s0217979220401505

[15] Montgomery, D. C. (2019). Design and Analysis of Experiments. Wiley, 688.

How to cite: Nguyen, T.-L. (2021). Modeling of external cylindrical grinding process using T1 tool steel. EUREKA: Physics and Engineering, 3, 85-98. doi: https://doi.org/10.21303/2461-4262.2021.001698 